\title{
11 Initial nasal clusters in Eastern and Western Austronesian
}

\author{
G.B. MILNER
}

Dyen (1965:294) refers to the growing inventory of Proto Austronesian phonemes to which he has himself made a notable contribution. His readiness to posit additional phonemes, however, is not matched by a marked disposition to call into question the structure of the Proto Austronesian morph. On the contrary he has stated in the same paper that any attempt to revise that basic concept (formulated by Dempwolff 1934-38) would prove to be more destructive than constructive (Dyen 1965:294).

The present paper is an attempt to show that, far from adding to Dempwolff's already formidable inventory, further progress in Austronesian comparative studies is more likely to be accomplished if a resolute attempt is made to reduce rather than to increase the number of reconstructed protophonemes by any method which can be shown to be in accord with the evidence available, whether that evidence be old or new. ${ }^{1}$ The present writer is aware that in this field considerable boldness is required to make up for the wealth of information concerning the entire Austronesian field such as perhaps only a Dempwolff could ever have mastered, in spite of (or perhaps owing to) his never having had electronic devices to assist him. Nevertheless this conference (see footnote 2) would not have served its purpose had it not presented an occasion to advance non-traditional theories. The point of view which is set out in the present article is based partly on a fairly careful re-examination of the evidence

\footnotetext{
I should like to take this opportunity of expressing my thanks to Professor E.J.A. Henderson, who saw the original draft of this article and suggested certain alterations. I am also grateful to Professor N.M. Holmer (1965), whose contribution to the second volume of Indo-Pacific Linguistic Studies provided the stimulus for this article, as well as to Dr W. Milke, who when he first read it sent me a number of helpful comments. [This is an edited version of the paper that first appeared in Lingua $14: 416-430$ (1965).]
}

Jan Tent and Paul Geraghty, eds Borrowing: a Pacific perspective, 201-214

Canberra: Pacific Linguistics, 2004.

(C) Copyright in this edition is vested with Pacific Linguistics. 
which was already available to Dempwolff, and partly on the experience of work in descriptive linguistics since 1946, with special reference to Fijian (for Melanesian) and Samoan (for Polynesian).

Teeuw (1965) has rightly deplored the relative neglect of Western Austronesian (i.e. Indonesian) comparative linguistics in more recent years in favour of Northem Austronesian (i.e. Formosan) and Eastem Austronesian (i.e. Oceanic) studies. However, given the dearth of fresh discoveries concerning Proto Austronesian origins in the Western Austronesian area, he would probably be the first to agree that the investigation of little-known or unknown languages in the peripheral regions should not be neglected. The continued use in the $1960 \mathrm{~s}$ of terms such as the 'RLD' and 'RGH' sound laws, which were first formulated in the 1880s, rather underlines the relatively small amount of progress made in Indonesian, as opposed to Austronesian, comparative studies.

To someone like the present writer, whose approach to Austronesian linguistics is from the point of view of the Oceanic region, this apparent tendency to underestimate the importance of 'peripheral' languages is reminiscent of Dempwolff's reluctance to accept Oceanic linguistic data on the same basis as evidence from Indonesian languages, and is hard to understand. Far from being regarded as questionable or irrelevant, the linguistic evidence of peripheral areas has, surely, been generally regarded in Indo-European studies as being of special importance, in that it was likely to have preserved in a fragmentary state archaic features which had disappeared from more central areas.

This article therefore represents an attempt to see whether certain features of peripheral languages can be used to make a fresh examination of the Proto Austronesian morph and of certain features of its phonetic structure.

As Milke (1961) reminds us, it was Kem (1886) who discovered that the Proto Austronesian (PAn) palatals had double reflexes in Samoan and Fijian, namely sometimes Samoan $s$, Fijian $s$ and sometimes Samoan $\emptyset$ (zero), Fijian $\varnothing$. This knotty problem proved to be particularly refractory for Dempwolff, who at the end of his life finally proposed a solution based on morphophonemic rather than on purely phonetic considerations. In doing so he reversed Kern's verdict (as well as the opinion that he had once held himself), and he left a considerable number of anomalies unaccounted for, notably a large number of doublets (Nebenformen) in Polynesian languages. Besides Milke, others have made attempts to solve this problem, particularly Grace (1959:19-23) and Haudricourt (1965:326-328) in his contribution to the first volume of these studies. The present writer has also touched on the problem of doublets (Milner 1963a).

Haudricourt, who uses arguments based on phonetic considerations, comes to a conclusion which is identical with that reached by Milke, who had not only tumed to a New Guinea language (Graged) for further evidence, but also made use of statistical techniques. That conclusion is as follows. In opposition to Dempwolff, who at the end of his career regarded Fijian $\delta$ and Samoan $s$ as the reflexes of the PAn oral (i.e. non-prenasalised) palatal consonants, but Fijian $s$ and Samoan $\emptyset$ as the reflexes of the palatal nasal clusters, Milke and Haudricourt see a stronger correspondence on the one hand between Samoan $s$ and Fijian $s$ and on the other between Samoan $\emptyset$ and Fijian $\partial$. Whereas, however, Haudricourt still regards the first pair as being reflexes of nasal clusters and the second pair, of non-prenasalised consonants, Milke (1961:175) states that he cannot find any firm evidence of a positive 
correlation between his Proto Oceanic (POc) reconstructed $s$ and $z$ phonemes and presence or absence of nasalisation in palatal clusters. He is therefore unable to give an explanation for the origin of the difference between $*_{s}$ and $*_{z}(1961: 175)$.

Thus, nearly eighty years after the publication of Kern's monograph, almost total deadlock still appears to prevail. If this state of affairs is to be remedied at all, it may be necessary to call into question certain basic assumptions which may not have been properly examined.

First, then, what was the evidence Dempwolff utilised and how strong was it? It will be remembered that the decisive factor for him was that, since nasal clusters did not occur in final position in Proto Indonesian (PIn), Fijian $\partial$ and Samoan $s$ must be regarded as the reflexes of oral (i.e. non-nasalised) consonants. But what of the rest of his evidence? The present writer has made a fresh count of all the Fijian and Samoan lexical items quoted by Dempwolff in the third part of his monograph as instances of reflexes of PAn palatals, and the results are given below. Where both forms of a doublet are mentioned, they have each been counted as one.

Table 1: Reflexes of PAn palatals in Samoan and Fijian (Dempwolff)

Proto Austronesian palatals

Number of reflexes

(i)

(ii)

In accordance with expectation Contrary to expectation

\begin{tabular}{lllll}
\hline & Fijian & Samoan & Fijian & Samoan \\
(a) $d^{\prime} t^{\prime} g^{\prime}$ or $k^{\prime}$ & $\partial: 43$ & $s: 41$ & $s: 33$ & $\emptyset: 23$ \\
(b) n'd $n^{\prime} t^{\prime} g^{\prime}$ or $\eta^{\prime} k^{\prime}$ & $s: 6$ & $\emptyset: 4$ & $\delta: 2$ & $s: 4$ \\
\hline
\end{tabular}

If we combine the suggestions made by Milke and Haudricourt, without introducing fresh evidence, we obtain the result which has been summarised in the following table. It will be seen that it is identical with Table 1 but for the switch of the second column (Samoan) to the fourth column (Samoan) and vice versa.

Table 2: Reflexes of PAn palatals in Samoan and Fijian (Milke and Haudricourt)

Proto Austronesian palatals Number of reflexes

In accordance with expectation Contrary to expectation

\begin{tabular}{lcccc}
\hline & Fijian & Samoan & Fijian & Samoan \\
(a) $d^{\prime} t^{\prime} g^{\prime}$ or $k^{\prime}$ & $\delta: 43$ & $\emptyset: 23$ & $s: 33$ & $s: 41$ \\
(b) $n^{\prime} d^{\prime} n^{\prime} t^{\prime} g^{\prime}$ or $\eta^{\prime}$ & $s: 6$ & $s: 4$ & $\delta: 2$ & $\emptyset: 4$ \\
\hline
\end{tabular}


It will be seen that if we are to retain Dempwolff's starred consonants as well as the bulk of his PAn vocabulary, the suggestions made by Milke and Haudricourt do not seem to solve the problem. ${ }^{2}$

In two articles published since 1961 (Milner 1963a \& b) the present writer has indicated that doublets could sometimes be explained by the large influx of loan words and interdialectal borrowings, especially in the area of Fiji, Tonga and Samoa, where extensive cultural and lexical interpenetration can readily be seen to have followed in the wake of both peaceful and war-like contacts. This suggestion cannot, however, account for all doublets, even within the Fiji, Tonga, Samoa area alone. Indeed a close examination of Dempwolff's starred PAn vocabulary supplemented by knowledge (obtained at first hand) of the semantic counterpart of starred lexemes reveals that not infrequently the connection between superficially divergent lexemes may have been overlooked, with the result that a number of superfluous starred morphs may have been set up.

Some of these protodoublets (or even prototriplets) Dempwolff quite clearly set up deliberately in order to reconcile what he judged to be otherwise irreconcilable reflexes, for instance:

$h a\left(\eta^{\prime}\right) g^{\prime} a v:$ day, sun $(60)^{3}$ a(n)dav: $:^{4}$ ditto (II)

$h a\left(\eta^{\prime}\right) g^{\prime} i:$ kin, blood relation (60) $a\left(\eta^{\prime \prime}\right) g^{\prime} i$ : ditto (12) t'inay: light (154)

t'inay: ditto (154)

pad'am : shut one's eyes (116)

pə(n) dom : ditto (116)

$$
\begin{aligned}
& \text { dá un : }:^{4} \text { leaf (39) } \\
& \text { (dd)avon : ditto (41) } \\
& \text { dahon: ditto (42) }
\end{aligned}
$$

In other cases, however, it is doubtful whether he realised that he was in actual fact setting up protodoublets or pseudo protodoublets. Thus:

t'úal: lever (155)

t'uvan: digging stick (159)
Fij. ðua: stick (used) to raise a fishnet (no Sam. reflex)

Sam. sua: turn the ground over (no Fijian reflex)

To anyone who has actually seen a digging stick in use, the semantic connection between a lever and a digging stick will be obvious. Moreover these two derivations ignore the Fijian:

2 During the session of the Conference [on Linguistic Problems of the Indo-Pacific Area, held in London in 1965] devoted to mathematical methods in linguistics, Milke commented on these tables and made the observation that they were not significant at the $10 \%$ level, and that this would tend to show that the relationship of PPn */s/ and */h/, and of Fijian /s/ and /ठ/ to Dempwolff's starred oral and prenasalised palatals was a purely random one.

3 These page references are to Dempwolff Vergleichende Lautlehre des Austronesischen Wortschatzes: Austronesisches Wörterzeichnis.

4 In these examples I have omitted the soft onset (weicher Vokal-Einsatz) and the sof tof fset (weicher Vokal-Absatz) indicated by ', but I have given it when as a 'weicher Zwischensatz' it occurs intervocalically. 
sua-ka 'to stab, pierce or spear' (while retaining hold of the weapon) given by both Capell (1941) and Hazlewood (1850).

With only Pratt's dictionary (1911 [1862]) at his disposal, however, Dempwolff cannot be blamed for not having realised that Sam. sua in addition to: 'tuming the ground over', also means: 'to lever' or 'prize something up', which seems to reinforce the correspondence proposed. We would therefore have:

PAn $t^{\prime}>$ Fij. $s$ and Fij. $\partial$ and PAn $t^{\prime}>$ Sam. $s$

The following other instances of pseudo protodoublets are also suggested:

d'uluk : insert (49)

$t^{\prime}$ ulup : penetrate (158)
Sam. su/u : stick into

Fij. đuruðuru : entry

Sam. su/u : press into sulufa $i$ : take refuge $u / u$ : enter

For Fijian, moreover, Hazlewood also gives sulu-ta 'to put the hand into a basket without opening it' (not mentioned by Dempwolff), and Capell has suru-ya 'to repair a mat (by inserting new strands into it)', so that we have:

PAn $t^{\prime}$ and PAn $d^{\prime}>$ Fij. $\delta$ and Fij. $s$

PAn $t^{\prime}$ and PAn $d^{\prime}>$ Sam. $s$ and Sam. $\emptyset$

It also seems likely that the following two lexemes are ultimately connected:

put'uh : innermost leaf (124)

putog' $^{\prime}$ navel (123)

Fij. vuso: youngest or middle-most leaves of the coconut, tail end of spear, smaller end of thing.

Fij. viðoviðo: navel

Sam. uso : umbilical cord

to which one can add: Sam. $u s o$ 'sibling' and Sam. $u \bar{o}$ 'friend', which would give:

PAn $t^{\prime}>$ Fij. $s$ and Fij. $\delta$

PAn $t^{\prime}>$ Sam. $s$ and Sam. $\emptyset$

Then there is the strong likelihood of a correspondence between:

pat'al: pair (115)

$d^{\prime} \partial(\eta) k a l: \operatorname{span}(47)$

t'aja: stand apart, bifurcate (148)
Sam. masay-a : twins (for which no Fij. or Sam. reflexes are given)

Fij. saya : crotch: i-saja: tongs

Fij. mbasana : branch

Sam. saya: fins (sic) of turtle

Sam. sasaya : bottle-rack

These three protolexemes are also perhaps connected with two others reconstructed by Dempwolff: 
ajap: open the mouth (15) (no Fij. or Sam. reflex given), and

Kabay: forking, bifurcation (85) (this last only if the possibility of a metathesis is confirmed, e.g. (?)kajap).

At first sight it may seem a little strange to seek a semantic connection between spans, twins, tongs, turtle flippers and branching, but it is fairly certain that all these and related concepts are subsumed under the concept of bif urcation. (The connection between the thumb and small finger of the hand outstretched to measure something and the flippers of a turtle will be obvious to those familiar both with turtles and measurements in spans.) Other Fij. and Sam. words (some of which were available to Dempwolff but which he did not utilise) reinforce this connection. Thus there is Fij. Øaya 'span' and Fij. saya 'thighs' (according to Hazlewood 'so called because they branch off from the body'), crotch, and also Sam. aya 'span'. These proposed etymologies can be summed up in the following formula:

$$
\begin{aligned}
& \text { PAn } t^{\prime} \text { and } d^{\prime}>\text { Fij. } \varnothing \text { and Fij. } s \\
& \text { PAn } t^{\prime} \text { and } d^{\prime}>\text { Sam. } s \text { and Sam. } \emptyset
\end{aligned}
$$

So far we have conf ined ourselves mainly to information which was already at the disposal of Dempwolff for both Samoan and Fijian and which he may or may not have utilised. Since the publication of the third part of [Dempwolff's] Vergleichende Lautlehre in 1938, however, Capell's New Fijian dictionary appeared in 1941 and the present writer has had the opportunity since 1955 of compiling an entirely new Samoan dictionary.

He has been struck by the large number of doublets occurring in both Fijian and Samoan which represent palatal and retroflex articulations in PAn. It will be seen (Milner 1963b) that the same situation obtains in the case of the reflexes of PAn retroflex articulations in Sam. and Fij. as has been outlined above for palatals, that is to say one may have $r$ and/or $n d r$ in Fijian and $l$ and/or $\emptyset$ (occasionally ?) in Samoan. The two problems are in fact almost exactly similar and further examples of these ambivalent correspondences will now be given: 
Table 3: Reflexes of palatal articulations

Fijian

(a) Medially

uðu-na: draw out, unsheath, withdraw

usu-maka: thread through, as a rope through a hole

$v u \delta i$ low, wet ground suitable for growing taro

vuðilevu: swamp

(?)vusi: trouble, sorrow, hard work

vuso(-ya)': effervesce; foam, froth

vиðu-ya: (of water) make turbid, muddy by stirring up)

vasi-a: scrape off crusts of roasted yams; split, esp.

firewood

vaði-a: cut yams in pieces (for planting)

(b) Initially

Jai-ta: have sexual intercourse

sai (or saisai): kind of throw-spear or arrow with a number of prongs bound together

¿eu-ta: carve on wood

seu-ta: scrape like a hen (looking for food)

doko-ta: be tied, fastened, caught, entangled, joined etc.

(so)soko: (of liquids) thick (mixed too thickly)

sokosokota: ditto

sova: bird's nest; kind of large round basket

saya: try hard to do something; be engaged in something, be in earnest

solo-ta: rub: rasp: dry oneself
Samoan

usu-i: stick, thrust

ü: reed

fui: water something

fuifui: steep, soak in water

(tau)fusi: swamp

uso: pith

(?) ?ōa: lather; be frothy, bubble

fasi: beat, kill, slash

(fa)fai: scrape (with a shell scraper)

sai-tia: bind (up)

saisai-tia: tie up

$\bar{a} i$ : sew, esp. sew two seams together

?eu: dab off, flick away

seu: steer (with an oar), mix a liquid, intercept a bird with a hand-net

$o$ ? $o$ : be reached, completed, achieved etc.; germinating coconut (i.e. the 'milk' of which has 'thickened, seized up')

so ${ }^{\prime} \mathrm{o}$ : be joined, connected

ofaya: nest

sofa: collapse

saya: get on with, attend to something aya: face up to, attend to

olo: rub; grate, grind

solo: wipe (esp. one's body with a towel) 
Other examples of doublets associated with palatal articulations in PAn were given in the paper presented at the 1961 study group (Milner 1963a) and need not therefore be reproduced here.

As for PAn retroflex articulations, with the evidence made available since 1941, a number of other entries can be added to Dempwolff's list of Fijian and Samoan reflexes. These swell the number of his ambivalent correspondences as the following table will show (retroflex consonants in PAn seem to be less productive than palatals and fewer examples of 'three-legged' and 'four-legged' correspondences have been found):

Table 4: Reflexes of retroflex articulations

\begin{tabular}{ll}
\hline Fijian & Samoan \\
\hline
\end{tabular}

(a) Medially

vondre: grasshopper

vure: (of water) spring up

(b) Initially

ndranu: sweet water (not salt)

(vei)ndranu-mi: place where salt and sweet water meet

ndrala: Erythrina ovalifolia (and indica) rara: Erythrina indica (both trees)

ndravu: ashes

ndravuisiNa: (of land) sunburnt parched

ravu: slaughter, smite

ravo: warm up food on live embers

tiro-va: look at oneself in a mirror, peep fue: creeper: fly-switch

lanu: colour (wash)

$(f a ? a) l a n u-m i a:$ wash off salt in fresh water anu: spit etc.

lala: Desmodium (a shrub)

âfu: wither; be heated for cooking

lafu(lafuā): (of ground) be barren

tio: (of eye and body movements) be sharp, lively

tilotilo: look, glance

Other examples of this type of correspondence occurring medially will be found in Milner (1963b:628).

In his 1961 article Milke expressed the belief that the regularity of correspondence which it was not possible to find between individual Oceanic languages and PAn, might nevertheless be established between groups of individual Oceanic languages with the object of reconstructing at any rate more firmly based POc phonemes. He gave as an instance Fijian $s$, Samoan $s$ and Graged $s$ (or $d$ ) on the one hand, and Fijian $\delta$, Samoan $\emptyset$ and Graged $\emptyset$ on the other, and, having obtained mathematical support for his belief, he set up two POc phonemes ${ }^{*} s$ and ${ }^{*} z$, the reflexes of which are claimed to be consistent in Oceanic languages but which need not necessarily always agree with Dempwolff's PAn consonants. Milke's ${ }^{*} s$ and ${ }^{*} z$ at 
least have the merit of being applicable to initial as well as medial consonants, but even so it is very difficult to share his belief that regularities of correspondence could be established in that manner, as Table 5 will indicate.

Table 5: Some reflexes of POc palatals

\begin{tabular}{|c|c|c|c|c|c|c|}
\hline & Graged & Samoan & Fijian & Sa'a & Rotuman & Tongan \\
\hline (a) Medial & & & & & & \\
\hline sleep & $\left.m o i^{i}\right)$ & moe & mоде & $\left.\operatorname{mode} e^{\mathrm{ii}}\right)$ & mose & mohe \\
\hline (of container etc.) & mamas & masa & матада & mamata & mamasa & maha \\
\hline dry; (of reef) & & & & & & \\
\hline $\begin{array}{l}\text { bare, awash (at } \\
\text { low tide) }\end{array}$ & & & & & & \\
\hline (b) Initially & & & & & & \\
\hline $\begin{array}{l}\text { miss; mistake; } \\
\text { be wrong }\end{array}$ & $\begin{array}{r}\text { sala (or } \\
\text { pala) }\end{array}$ & sala & dala & tala & sara & hala \\
\hline road, path & dal & ala & sala & tala & sala & hala \\
\hline outrigger & sam & $a m a$ & дama & sama ${ }^{\text {ii }}$ ) & sama & hama ${ }^{\text {iv }}$ ) \\
\hline $\begin{array}{l}\text { bad, wicked; } \\
\text { forbidden }\end{array}$ & $\begin{array}{r}\text { alan (or } \\
\text { salan) }\end{array}$ & $s \bar{a}$ & $\partial \bar{a}(t a)$ & $t a^{?} a$ & $-s a^{?} a$ & $h \bar{a}($ sia $)$ \\
\hline
\end{tabular}

i) to be unwilling, disinterested;

ii) listless, faint of heart;

iii) (of canoes etc.) abreast of one another;

iv) note also ama 'windward side' (i.e. outrigger side) of canoe etc.

I have tried elsewhere (Milner 1963b) to show that as regards doublets, consonants in Oceanic languages which are reflexes of PAn retroflex consonants behave precisely in the same way whether they occur medially or initially, and I drew the conclusion that for the protolanguage from which both Fijian and Samoan are derived (i.e. Dempwolff's Urmelanesisch and Milke's Proto-Ozeanisch) one was forced to posit an optional feature of prenasalisation in initial as well as in medial consonants.

It now seems clear that the evidence available from doublets in Fijian and Samoan which are correlated with PAn palatal consonants reinforces this suggestion.

That being so, can one expect to find any evidence of optional prenasalisation in the case of bilabial, alveolar and velar initial consonants in those two languages? That is to say, before one can be quite certain that the initial prenasalisation of the stops was general in POc, one should also be able to identify initial doublets in the case of bilabial, alveolar and velar consonants, at any rate in Fijian, where the reflexes are $m b$ and $v, n d$ and $t, \eta g$ and $k$ respectively, and perhaps in Samoan-if only in the case of the two separate reflexes for the bilabials ( $p$ and $f$ ). The alveolars and the velars having only one reflex each ( $t$ and $k$ respectively) in Samoan, no doublets are to be expected there. 
The following table sets out some of the evidence obtained from an examination of the Fijian and the Samoan dictionaries with those possibilities in mind:

Table 6: Fijian and Samoan doublets showing prenasalisation of non-palatal initial consonants

\section{(a) Fijian bilabials}

beti-a: pluck fruit

veti-a: pluck fruit

bora-ta: prohibit, speak angrily

vora-ta: resist a command, oppose, withstand bono-ta: block, stop; dam up vono-ta: inlay; make panels (as for a plank-built canoe) butu-ka: stamp, tread upon $v u t u-k a$ : pound (as with a pestle)

\section{kari-a: scrape \\ qari-a: graze, scrape}

(b) Fijian alveolars

dago-na: trunk (of body or tree)

tago-na: interval, section (esp. between nodes of bamboo or sugarcane)

dede-ku: spread out, open (hand, fish etc.)

tete-va: spread, stretch out (e.g. branches of a tree)

(vaka)deme-na: do something slightly, strike lightly, pamper a child teme-ka: eat sparingly, like a sick man, take small bites daro-ya: prevent, prohibit taro-va: hinder, prevent

dibi-na: hip; thigh; pelvis tibi-ka: bend sharply, fold, thatch doa: heartwood of a tree (ulu)toa: weighted head of a dart (tiqa)

duki-a: make a noise under water (to drive fish into the net) tuki-a: beat or knock with fist, hammer

(c) Fijian velars

qasi-a: strip off (leaves or shell or bark)

kasi-a: shed bark; pluck of f pandanus leaves qilo: hollow in a tree (filled with water)

kilo: low place, ravine, hollow

ququ-na: hoof of an animal

$k u k u-n a$ : nail of finger or toe

(d) Samoan bilabials

pō: slap, swat, clap

(fo)fō: massage

fatu: heart, seed, core

patu: swelling, lump

fole: look pale, ill, anaemic

fulu: feather, fur, down

(po)pole: be worried, anxious 
With all this evidence before us, I now wish to put forward the thesis that the optional prenasalisation of initial consonants as a phonetically distinctive feature ${ }^{5}$ (as opposed to homorganic prenasalisation by accretion ${ }^{6}$ or substitution ${ }^{7}$ as a morphophonemically distinctive feature), was at one time general in Austronesian languages and was not restricted to Oceanic languages only. ${ }^{8}$

Until now, to my knowledge, no words of Sanskrit origin have been discovered in Oceanic languages. It follows that since they are directly descended from languages which split off from the parent stock before Sanskrit loan words began to appear in Austronesian, Oceanic languages must be regarded as being, in one sense, of considerable antiquity. Moreover, since over large areas Oceanic cultures appear to have remained almost untouched by European or Asian influences until the Renaissance or even much later, there is a prima facie expectation that these languages will have preserved archaic features which were once common to the entire Austronesian area and which have all but disappeared from the centre of it. Moreover it is also possible that because of their peripheral and isolated situation they havenot participated in changes that took place in the more central areas subsequent to the time when the speakers of Oceanic languages first settled upon the islands of the Western Pacific.

As a case in point there is the widespread feature of homorganic nasalisation by accretion or substitution in Indonesian languages, which has morphophonemic or, to use a more traditional term, grammatical functions. This is of course not Oceanic. ${ }^{8}$ The question arises therefore whether Oceanic languages have lost this feature, or whether it is a relatively late development in which as peripheral languages they have not participated.

It seems, to say the least, arguable that the following situation is more than a coincidence: on the one hand the Eastern (Oceanic) languages frequently have prenasalised stops occurring initially as well as medially, prenasalisation being of ten a phonetically distinctive feature ${ }^{5}$ in both positions. On the other hand in the Western (Indonesian) languages prenasalisation of the stops only occurs medially as a phonetically distinctive feature, and where initial it occurs as a morphophonemic feature not limited to the stops but of ten also affecting other consonants. It is therefore reasonable to suppose that at a very early date throughout the entire Austronesian area there was (as there still is frequently in contemporary Oceanic languages) the possibility of a phonemic distinction between prenasalised voiced stops in free distribution and non-prenasalised voiceless stops also in free distribution. Subsequently, however, in the central part of the linguistic area, i.e. in that now occupied by Indonesian languages, in initial

5 That is to say prenasalisation by accretion (though not by substitution also, as in the Dempwolffian use of the word Pränasalierung) and as the phonetic realisation of a phonemic (as opposed to a morphophonemic) distinction.

Nasaler Zuwachs.

\section{Nasaler Ersatz.}

8 Since this paragraph was written Milke has reminded us that in Jabêm homorganic prenasalisation by accretion seems to have functions which can at least partly be described as morphophonemic. The validity of the above statement therefore needs to be examined. Alternatively this might provide another way of defining more precisely the boundary between Western and Eastern Austronesian. 
position the prenasalised stops ceased to be in free distribution. The reason for that change is that the nasal component had become a grammatically conditioned (as opposed to a phonetically unrestricted) distinctive feature, through a process of accretion to (or substitution for) the corresponding homorganic oral articulation. Later this feature may, by analogy, have spread to other consonants besides the stops. Such a development could well, given the geographical distribution of Austronesian languages, not have affected Oceanic languages, and might account for the fact that the initial and medial consonants of the latter behave alike.

Now if such a thesis is to be upheld, there should be at least one other peripheral area where the occurrence of prenasalised initial consonants is not always governed by morphophonemic principles.

This requirement is met in Madagascar, where as Dempwolff (1934-38, vol. 2, pp.92-95) shows in the case of Hova (Merina), there is not only a tendency for the Hova reflex of a PAn medial nasal cluster to be aberrant $(\S 105 f$ and $g$ ), but there is also a tendency to prenasalise initial consonants in contexts which cannot be accounted for by reference to the regular morphophonemic processes which Hova shares with other Western Austronesian languages.

In particular Dempwolff shows that the Hova reflexes of certain PAn initial consonants are undoubtedly reduced nasal clusters, though he is unable to offer a satisfactory explanation for this $(\S 105 h$ and $i)$. Despite the evidence of Hova, added to that of Melanesian and Polynesian, he could not bring himself to reconstruct optionally prenasalised initial consonants on the ground that these never, or hardly ever, occurred in any other Indonesian language. ${ }^{9}$

As Dahl (1951) recalled in his comparative work, Malagasy is relatively 'younger' in the sense that the approximate period of the settlement of Madagascar by speakers of Austronesian languages can be fixed. It seems clear that this must have happened long after the settlement of the islands of the Western Pacific, as evidenced by the fact that Hova (Merina) has many words of Sanskrit origin. It is possible therefore that if the point of view advocated in this paper is correct, in its treatment of initial consonants Malagasy may represent a chronologically intermediate stage between Oceanic and Indonesian languages.

Considerations of space and time make it impractical to work out in detail the consequences which would logically follow the adoption of the view advocated in the present paper, but it seems clear that it would be possible to simplify the already extremely unwieldy structure of PAn consonants which the latest discoveries in Formosa threaten to complicate even further. Haudricourt (1965) has shown some of the ways in which this simplification could be achieved. Is it likely, for instance, that we shall always have to look upon Dempwolff's $m b \neq$ $m p \neq b \neq p$ as immutable and fixed for all time?

Finally this approach may even offer a way of solving some of the problems which have been subsumed under such terms as 'the RLD law', 'the RGH law' etc. which, as Teeuw has reminded us, still await a solution. Thus the distribution of isoglosses for initial $r, l$ and $d$ in

9 The relevant passage in the second part of Dempwolff's (1934-38) work (Vergleichende Lautlehre des austronesischen Wortschatzes: deduktive Anwendung, 95 §105, i), deserves to be quoted in full: 'Die Anlaute des UIN., die im Ho(va) mit reduzierten Nasalverbindungen auftreten, werden hier ïberhaupt nicht zu fakultativen Nasalverbindungen ergänzt, da man eine Nasalverbindung der Anlaute nur im Ho. sonst aber in kaum einer anderen indonesischen Sprache (wohl aber in melanesischen und polynesischen) antrifft.' 
Indonesian languages might conceivably be explained by reference to the various ways in which different languages have preserved what was originally an initial nasal cluster and which now only survives intact in a relatively 'obscure' language such as Fijian where, for instance, 'leaf' is ndrau, 'blood' is ndrā, 'ashes' is ndravu, 'lake, pond' is ndrano and 'twins' is ndrua (complementing rua 'two'). It is true that 'hear' is royo, but there is a strong indication that it is complemented by ndrona- as in ndronandrona 'hoarse', and in ndroyandroya wale 'cry oneself hoarse, grieve, mourn'. Compare for instance Dempwolff's

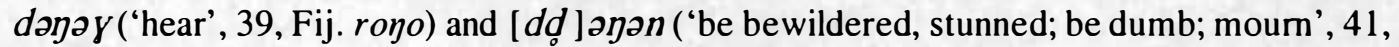
Sam. fa 'aloloyo 'be silent') which, taken together, may also represent a pseudo protodoublet.

It should be noted, incidentally, that in Fijian $n d r$ represents a prenasalised rolled consonant, without any trace of an anaptyctic vowel between the postalveolar contact and the roll. It may be argued therefore that there is greater likelihood that where other languages have $d$ or $r$ corresponding to Fijian $n d r, d$ and $r$ are the reflexes of different components of what was once a single articulation (as it has remained in Fijian), rather than that the Fijian $n d r$ should represent a kind of haplology of a disyllabic group.

\section{References}

Capell, Arthur, 1941, A new Fijian dictionary. Sydney: Australasian Medical Publishing Company.

Dahl, Otto Christian, 1951, Malgache et maanyan. Oslo: Egede Instituttet.

Dempwolff, Otto, 1934-38, Vergleichende Lautlehre des austronesischen Wortschatzes. 3 vols. Berlin: Vohsen.

Dyen, Isodore, 1965, Formosan evidence for some new proto-Austronesian phonemes. Lingua 14(1):285-305.

Grace, George W., 1959, The position of the Polynesian languages within the Austronesian (Malayo-Polynesian) language family. Memoir 16 of International Journal of American Linguistics and Supplement to International Journal of American Linguistics 25(3). Baltimore.

Haudicourt, André G., 1965, Problems of Austronesian comparative phonology. Lingua 14(1):315-329.

Hazlewood, D., 1850, A Feejeean and English and an English and Feejeean dictionary. Vewa [Viwa, Fiji]: Wesleyan Mission Press.

Holmer, Nils M., 1965, Types of consonant alternation in Austronesian, especially Melanesian. In G.B. Milner and Eugene J.A. Henderson, eds Indo-Pacific linguistic studies part 2, 475-494.

Kem, Hendrik, 1886, De Fidjitaal: vergeleken met de hare verwanten in Indonesië en Polynesië. Amsterdam: Johannes Muller.

Milke, Wilhelm, 1961, Beiträge zur ozeanischen Linguistik. Zeitschrift für Ethnologie $86(2)$.

Milner, George, 1963a, Notes on the comparison of two languages (with and without a genetic hypothesis). In H.L. Shorto, ed. Linguistic comparison in South East Asia and 
the Pacific, 28-44. London: School of Oriental and African Studies, University of London.

1963b, Liquid consonants and the relationship of Polynesian to Austronesian languages.

Bulletin of the School of Oriental and African Studies 26(3).

Pratt, George, 1911 [1862], Grammar and dictionary of the Samoan language. 4th edition. Apia: Malua Printing Press.

Teeuw, A., 1965, Old Balinese and comparative Indonesian linguistics. Lingua 14(1):271284. 